\title{
Environmental aspects of designing urban infrastructure for smart cities
}

\author{
Alexey Dubrovsky, Anastasia Ilinykh*, Galina Yurina, and Tatyana Mezhueva \\ Siberian State University of Geosystems and Technologies, Novosibirsk, Russia
}

\begin{abstract}
The article discusses the need to develop elements of smart rational design of urban space with recreational areas and focus on creating an environmentally friendly environment. The authors proposed a sequence of measures to control the recreational provision of the territory of the settlement. The authors highlight the factors influencing the development of underground urban space and the principles of the formation of an ecocity as promising directions for organizing urban space. The article presents the principles of rational organization of urban space.
\end{abstract}

\section{Introduction}

Recreation at present is an important element of the modern territorial arrangement, it helps and contributes to the health of a person, as well as the restoration of strength and health [1]. This term is over 30 years old. Developers of plans for the development of the territory began to include green recreational areas in their projects. The population needed places within settlements with a clean, unpolluted environment, landscaping, and other constructive elements conducive to recreation. Garden plots, which are for the personal use of citizens play the role of recreational areas for the population in many settlements of Russia and large metropolitan areas [2]. This approach does not solve the problem of deteriorating well-being of the population of large cities. Often people have the "urbanist" syndrome - a youthful lifestyle, fatigue.

Smart design technologies apply to various complex projects for the development and arrangement of the territory [3]. Geodesign technology allows us to minimize the cost of building a real estate object because of the optimal placement of this object in the natural landscape $[4,5]$. "Smart" design saves money at the stage of the primary development of the territory, for example, it is minimizing the volume of earthworks and reclamation works, minimizing landscaping work, since most often natural vegetation is preserved. As a result, the costs of operating the territory are reduced, caused, for example, by the need to carry out additional landscaping or landscape design of the territory.

\footnotetext{
* Corresponding author: ilinykh_al@mail.ru
} 


\section{Materials and methods}

In the practice of urban planning, the methods of geoinformation analysis and geomodeling are used in the organization of a rational land use system and in measures to maintain optimal living conditions for the population. Recreational land use is a complex geographically distributed multicomponent system. The urban environment is a complex of diverse functional areas. The primary task of the recreational zones of the city is to ensure the restoration of strength and health of the population using the natural-climatic, landscape-composition and engineering-technical features of the territory.

\section{Results and discussion}

The concept of smart building design and construction has developed over the years in modern urban planning. Smart home technologies are multifaceted and cover the entire range of all kinds of improvements in the quality properties of a real estate object.

A smart home is a system that ensures safety, resource saving and comfort for all users [6].

A smart city is an urban planning concept for integrating a variety of information and communication technologies (ICT), including the Internet of Things systems. The purpose of Smart cities is to manage urban infrastructure, healthcare, education, transport, security, housing, and communal services.

The British Standard Institution (BSI) views a smart city as "the effective integration of physical, digital and human systems in an artificially created environment to ensure a sustainable, prosperous and inclusive future for citizens" [7].

New York is one of the safest megacities in America for recreation [8]. According to experts, $97 \%$ of city residents need only 10 minutes to walk from their house to the nearest park or garden. This figure for a city with 8 million inhabitants is one of the best in the world.

Each "smart city" has standards and properties that should correspond to the direction of development of such cities. The properties of a "smart city" include [9] urbanization, smart technologies, quality of life, mobility, virtualization, personification, and infrastructure modernization.

Earlier studies of the recreational provision of the territory of Novosibirsk (Russia) showed that in some estimated blocks the deficit is $85 \%$ or more of the standard of provision for 1 person. The results of the study are presented in detail in [10].

Even on the territory of Novosibirsk, there are many examples when developers build up recreational zones to the detriment of the aesthetic. Development of forest park zones in cities exacerbates the problem of recreational provision of the territory of settlements.

The authors present a sequence of measures to control the recreational provision of the territory of a settlement (Figure 1). 


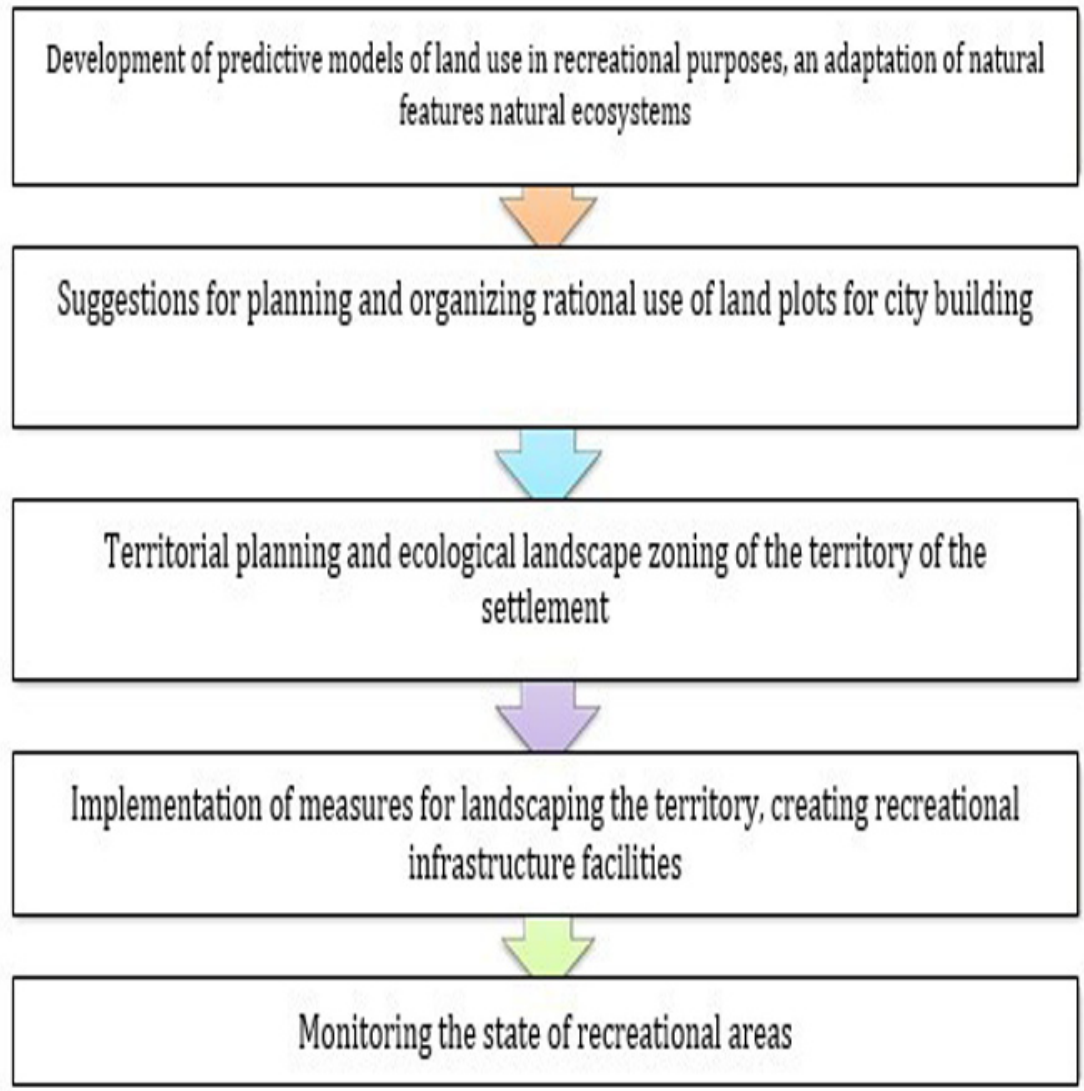

Fig. 1. The sequence of measures to control the recreational security of the territory of the settlement.

One of the promising areas of rational organization of urban space is the use of urban underground space. Analysis of the goals and directions of the development of urban underground space allowed us to highlight the promising factors shown in Figure 2. 


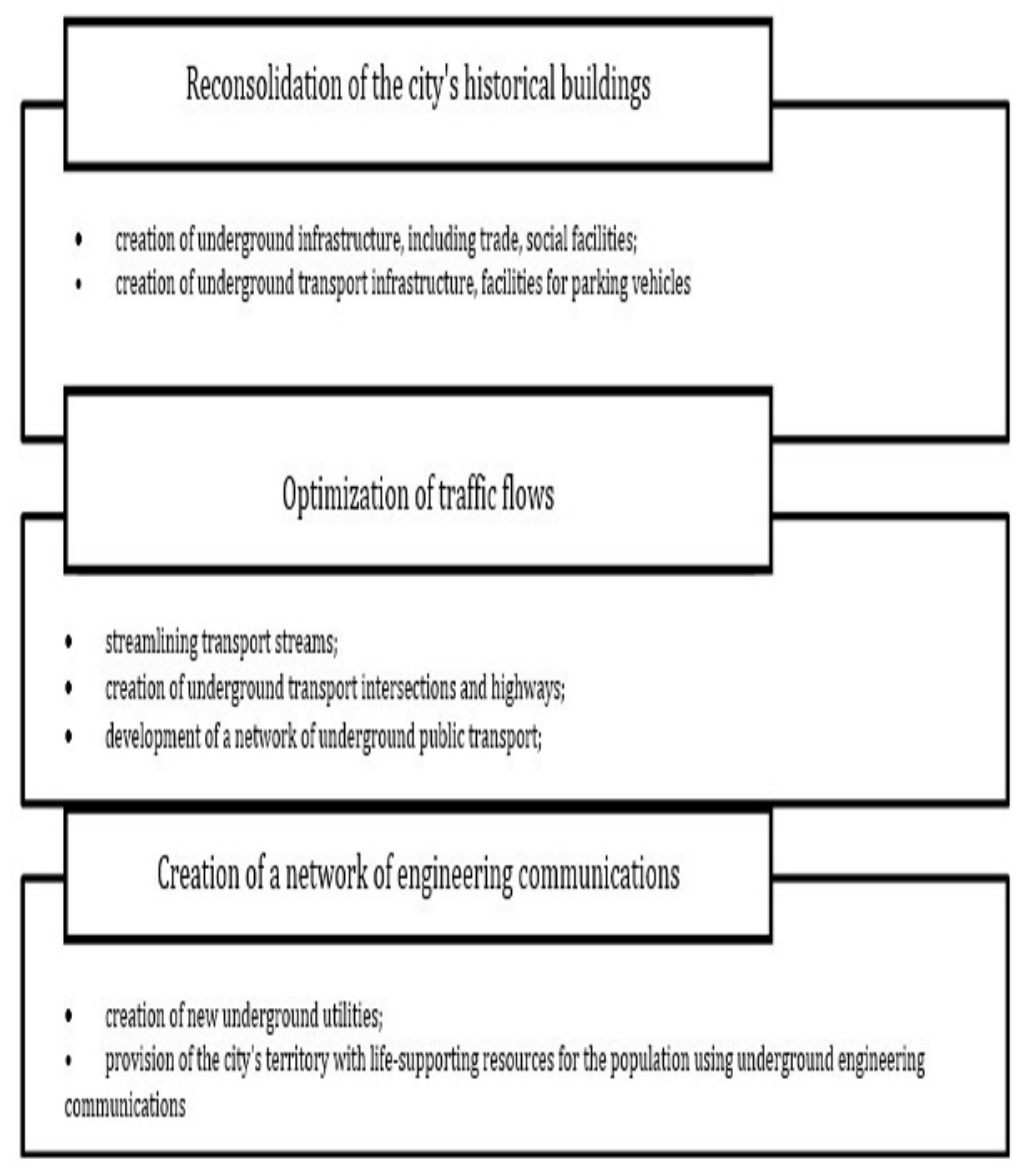

Fig. 2. Factors influencing the development of underground urban space.

An updated concept of ecocity appeared in the 70s of the last century. 3 main provisions for the formation of ecocity were presented (Figure 3). 


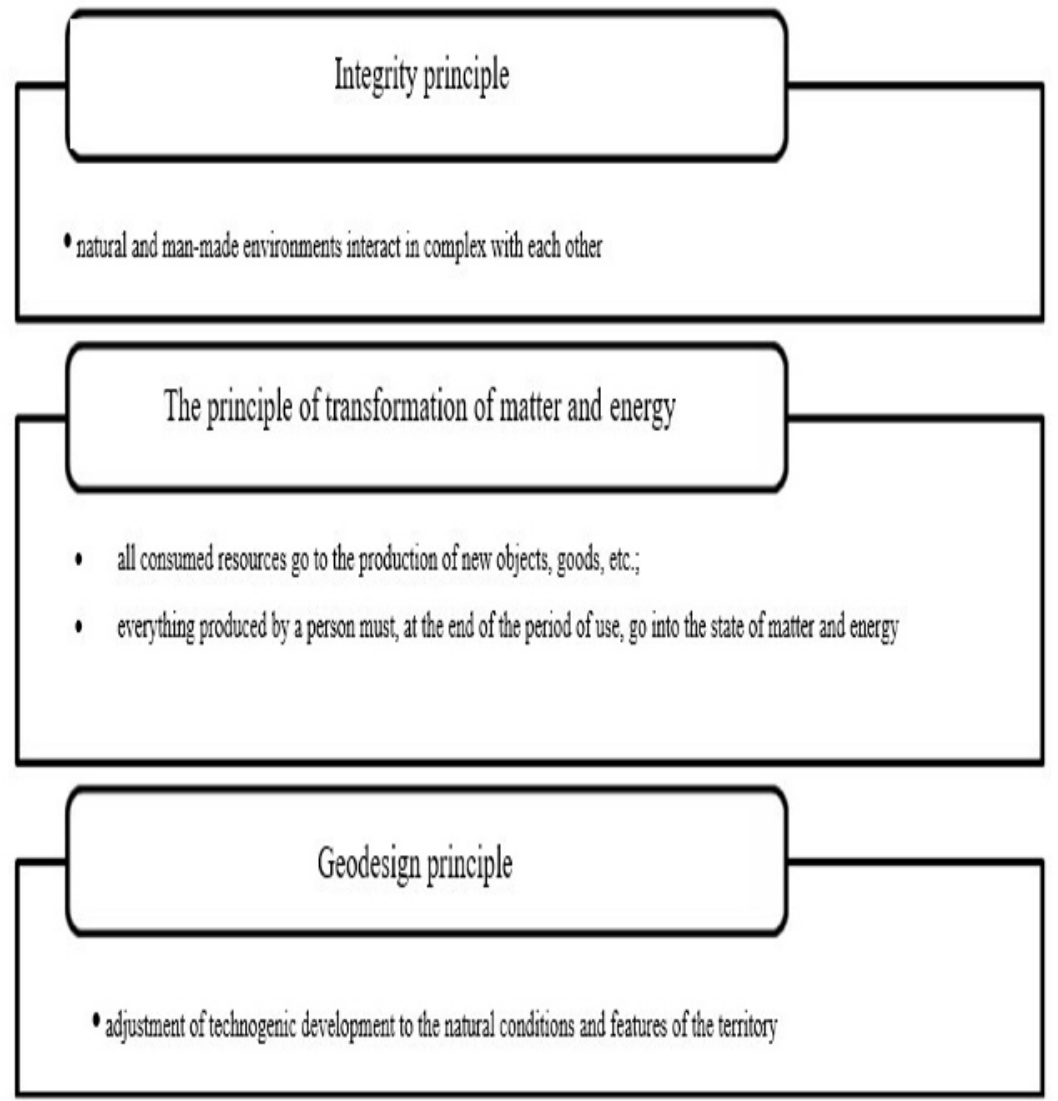

Fig. 3. Ecocity formation principles.

The concept of a «smart city» contains three basic parameters: adaptability, intellectualization, focus on lifestyle.

The areas that primarily need intellectual modernization are the economy, infrastructure, and urban management (Table 1) [11].

Table 1. The most important directions for the development of a «smart city».

\begin{tabular}{|c|c|c|}
\hline $\begin{array}{c}\text { Innovative } \\
\text { economy }\end{array}$ & $\begin{array}{c}\text { Urban } \\
\text { infrastructure }\end{array}$ & $\begin{array}{c}\text { Public } \\
\text { administration }\end{array}$ \\
\hline $\begin{array}{c}\text { Innovations in } \\
\text { industry, clusters, } \\
\text { city districts }\end{array}$ & Transport & $\begin{array}{c}\text { Administrative } \\
\text { services to citizens }\end{array}$ \\
\hline $\begin{array}{c}\text { Smart } \\
\text { Workforce: } \\
\text { Education and } \\
\text { Employment }\end{array}$ & Energy / Utilities & $\begin{array}{c}\text { Representative and } \\
\text { direct democracy }\end{array}$ \\
\hline $\begin{array}{c}\text { Creation of } \\
\text { knowledge- } \\
\text { intensive } \\
\text { companies }\end{array}$ & Environment / safety & $\begin{array}{c}\text { Services for } \\
\text { citizens: quality of } \\
\text { life }\end{array}$ \\
\hline
\end{tabular}

We found advanced developments in the planning and organization of the territory of settlements in the concept of urbanism. The concept of urbanism is based on sustainable 
and environmentally-friendly planning of urban space. The key principles are the following provisions (Figure 4).

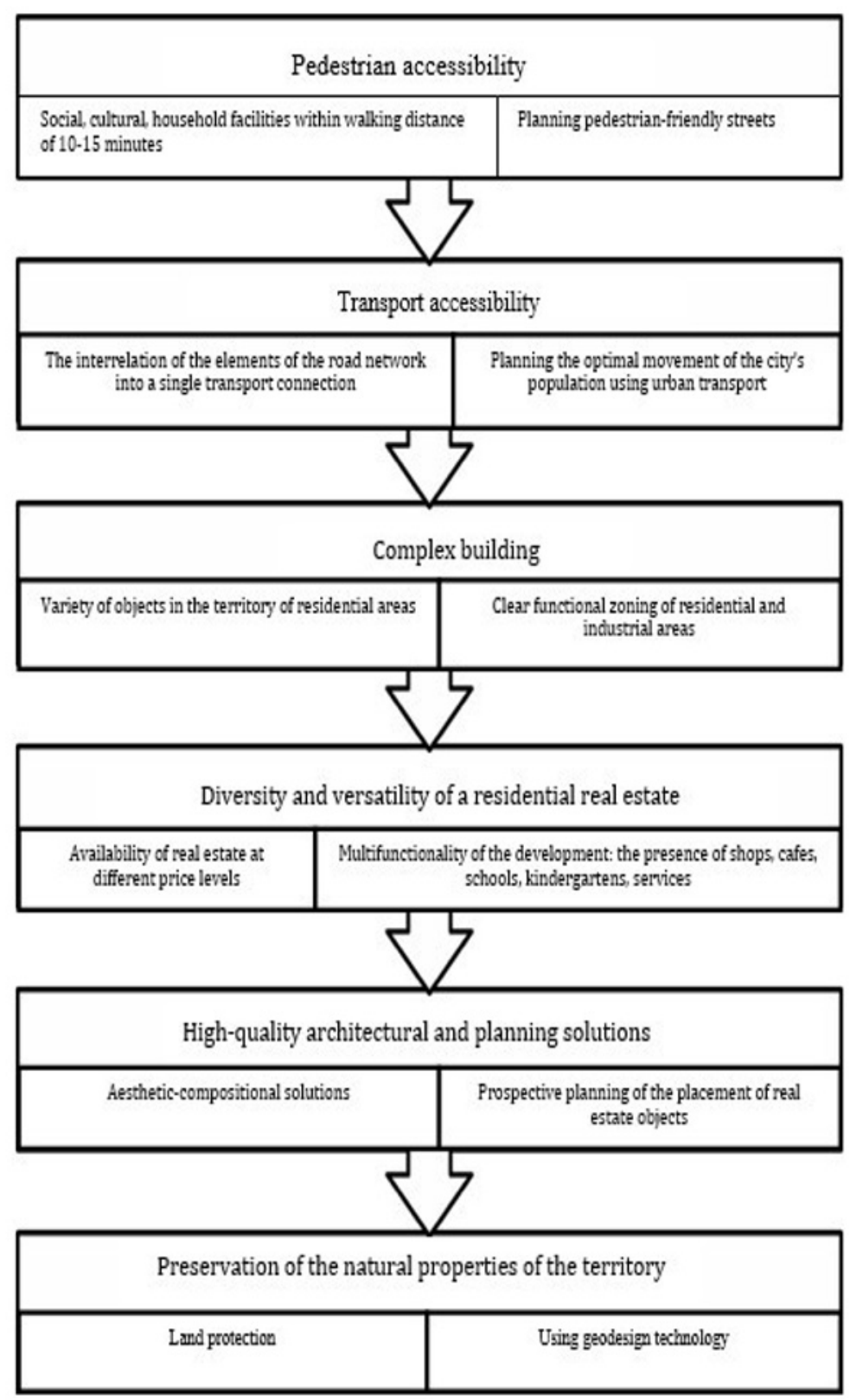

Fig. 4. Principles of rational organization of urban space.

The key principle of a "smart city" is the reuse of resources, reuse of data in various departmental information systems and infrastructures (server capacities, sensors, video cameras, etc.).

As a result of their implementation, end-to-end technologies will give an incentive to improve the quality of life and management of various sectors of the urban economy while reducing resource consumption and the comfort of the urban environment. 


\section{Conclusion}

The population of modern megalopolises, medium and small settlements needs green forest parks, places for recreation in nature and in open space.

Such a not comforting tendency occurs in the territory of many modern developing, intensively built-up settlements. The lack of recreational areas is not compensated, and the existing recreational facilities are being reduced because of intensive development.

The goal of creating a "smart city" is to ensure the most comfortable life, environmental friendliness, energy intensity, safety, and a wide range of opportunities.

\section{References}

1. J. D. Blower, A. L. Gemmell, G. H. Griffiths, K. Haines, A. Santokhee, X. Yang, Environmental Modelling \& Software, 47, 218 (2013)

2. A. V. Dubrovsky, I. T. Antipov, A. I. Kalenitsky, Int. J. of Advanced Biotechnology and Research, 9(1), 1185 (2018)

3. Five real solutions for a smart city: an example from Russia, Tass, https://tass.ru/

4. G. G. Kurierova, Ecology of the object world as a design strategy in the post-industrial period, 132 (2008)

5. V. I. Tatarenko, E. A. Popp, Izvestiya Vuzov «Geodesy and aerophotosurveying», 4, 165 (2014)

6. G. V. Esaulov, Architecture and construction, 5, 56 (2017)

7. M. A. Shneps-Shneppe, Int. J. of Open Information Technologies, 2, 11 (2016)

8. V. A. Gorokhov, Greening of foreign cities Landscape architecture and green building, http://landscape.totalarch.com/

9. Designing smart homes, Habr, https://habr.com/

10. A. V. Dubrovsky, Int. scientific. conf. "Remote sensing methods of the Earth and photogrammetry, environmental monitoring, geoecology" (SGUGiT, Novosibirsk, 2019), 135

11. Smart city. Concept, standardization and implementation of smart city, Portal about modern technologies of mobile and wireless communications, http://1234g.ru/ 